\title{
AURELIO ALMAGRO GRACIA MEDICINA Y SOCIALISMO EN EL EXILIO (1881-1973)
}

\author{
ÁNGEL MEDINA LINARES* \\ UNIVERSIDAD DE CÁDIZ
}

\begin{abstract}
RESUMEN
El desarrollo de la Guerra Civil española trajo consigo el exilio de miles de republicanos debido a los horrores vividos y sobre todo a la represión ejercida por los sublevados. Un éxodo sin precedentes en la historia española que se iba intensificar en los compases finales del conflicto y de la propia República, cuyo gobierno y partidarios tuvieron que establecerse en los países de acogida mientras que el régimen franquista se instauraba en España. Entre esos exiliados estaba Aurelio Almagro Gracia, médico y dirigente del PSOE de la provincia de Cuenca que logró refugio en México, donde forjó una nueva vida marcada por el auxilio de los más necesitados y la reconstrucción del socialismo.
\end{abstract}

PALABRAS CLAVES: Cuenca, medicina, socialismo, exilio, México

*angelmedinalinares@hotmail.com 


\title{
AURELIO ALMAGRO GRACIA MEDICINE AND SOCIALISM IN EXILE (1881-1973)
}

\author{
ÁNGEL MEDina LINARES* \\ UNIVERSIDAD DE CÁDIZ
}

\begin{abstract}
The development of the Spanish Civil War brought with it the exile of thousands of republicans due to the horrors experienced and above all the repression exerted by the rebels. An exodus unprecedented in Spanish history that was to intensify in the closing stages of the Republic, whose government and supporters would have to establish themselves in the host countries while the Franco regime was established in Spain. Among these exiles would Almagro Aurelio Gracia, physician and leader of the PSOE in the province of Cuenca who took refuge in Mexico, where he forged a new life marked by the aid of the needy and the reconstruction of socialism.
\end{abstract}

KEYWORDS: Cuenca, medicine, socialism, exile, Mexico

Enviado: $25 / 05 / 2020$

Aceptado: 4/11/2020

*angelmedinalinares@hotmail.com 


\section{UNA HISTORIA DEL EXILIO}

El exilio republicano español desencadenado a raíz de la Guerra Civil y la instauración de la Dictadura franquista es un proceso histórico que ha sido estudiado extensamente por la historiografía española y extranjera; sus protagonistas, los caminos tomados por los mismos, los países de acogida, así como la vida desarrollada durante el exilio han sido objeto de estudio de diferentes investigaciones. Dentro de este contexto histórico los aspectos que han recibido un mayor interés han sido aquellos relacionados con los miembros más destacados de la política y la élite intelectual de la primera década del siglo XX de nuestro país. Sin embargo, en el amplio abanico de cuestiones históricas que ofrece el exilio republicano español, existe una enorme diversidad de historias y vivencias personales que hoy en día se escapan de nuestro conocimiento y que están relacionadas con la masa de población que huyó de los terrores de la Guerra, que sufrieron las penurias del exilio y que no tuvieron la misma suerte que los dirigentes políticos y los intelectuales.

Entre este amplísimo contingente de personas exiliadas debemos incluir también a políticos, intelectuales, artistas y profesionales de diferentes sectores, que pese a no estar en el "escaparate" público de la época, jugaron un papel clave en el transcurso del propio exilio. En este grupo encontramos a Aurelio Almagro Gracia, un exiliado más que hasta hoy en día no ha recibido el interés investigador merecido. Natural de Zaragoza, Aurelio Almagro fue un político, médico e intelectual que desarrolló su carrera política y profesional en la década de los años 20 y 30 del pasado siglo. Perteneciente al PSOE fue una figura clave en la evolución y desarrollo de su partido en la provincia de Cuenca llegando a elección de diputado en las Cortes republicanas en 1931 y 1936. Un personaje dedicado a su tierra de adopción que tras el golpe de estado militar de 1936 y el transcurso de la Guerra Civil se vio obligado a exiliar por el temor a las represalias del régimen dictatorial que se instauraba en nuestro país. Un proceso de exilio que llevará a Aurelio Almagro Gracia a México donde tuvo un papel clave en la reorganización del PSOE y en el auxilio de miles de exiliados republicanos.

Con la necesidad que conlleva poner en conocimiento la vida de cada uno de los españoles que tuvieron que marchar al exilio, en las siguientes páginas se analiza la trayectoria de Aurelio Almagro Gracia, destacando las dificultades sorteadas, los caminos tomados, las pérdidas familiares, las penurias económicas o la dificultad para establecer un nuevo hogar fuera de España. Sin embargo, esta investigación va más allá al analizar la exis- 
tencia de redes culturales y políticas, formales e informales creadas entre los exiliados republicanos en México. Una cuestión que como veremos favorecerá la formación del imaginario y la identidad del exiliado, ya que fueron estas redes las que fomentaron a su vez la creación de instituciones que permitieron a los exiliados y a sus descendientes desarrollar proyectos políticos, profesionales, culturales e intelectuales.

Respecto a las redes del exilio en las que estuvo inmerso Aurelio Almagro se hará referencia a dos aspectos diferentes pero relacionados entre sí: la continuidad política y el auxilio de los exiliados. En primer lugar, veremos cómo se trasplantaron modelos de organización política que ya existían en España y que estaban vinculados a grupos políticos que, a pesar de estar dispersos en diferentes países, lograron desarrollar instituciones, métodos y proyectos que habían iniciado en España pero que en el exilio tuvieron que ser remodelados. En este caso es fundamental la reorganización política del PSOE en México, el cual se encontraba en plena descomposición debido a la división producida entre otras razones por la derrota republicana en la Guerra Civil y donde Aurelio Almagro alcanzará un puesto de relevancia coincidiendo con miembros históricos del partido. En segundo lugar, también veremos como la solidaridad y el auxilio de los más necesitados se verá reflejado en la creación de diferentes organismos encargados de la asistencia sanitaria de los exiliados españoles que llegaban a los diferentes países de acogida. Unas organizaciones de ayuda a los exiliados donde también estará presente Aurelio Almagro realizando una enorme labor de asistencia médica en instituciones sociales como la Junta de Auxilio a los Republicanos Españoles (JARE) o la Benéfica Hispana, las cuales no han recibido el interés investigador necesario pese a la gran labor realizada por sus integrantes.

Para reconstruir toda la vida y la trayectoria política y profesional de Aurelio Almagro Gracia y ante la falta de investigaciones previas, salvo las excepciones de los diccionarios biográficos de los diputados socialistas de la República existentes ${ }^{1}$, ha sido fundamental el análisis de las fuentes

1. Las referencias se encuentran, por un lado, en el trabajo de investigación sobre el Grupo Parlamentario Socialista en la Segunda República de Aurelio Martín Nájera, donde encontramos una breve biografía sobre Aurelio Almagro, así como datos de su trayectoria política, en especial su labor como diputado parlamentario en la legislatura de 1931 y de 1936: P. Barruso Barés y A. Martín Nájera (2010). Por otro lado, donde encontramos una mayor información es en el completísimo estudio realizado por Leandro Álvarez Rey sobre Los Diputados por Andalucía de la Segunda República (1931-1939), un proyecto que a través de tres diccionarios biográficos explora la trayectoria de los 
documentales de la época. Por un lado, de especial relevancia, ha sido la consulta de la Fundación Pablo Iglesias (FPI) que conserva la documentación histórica del PSOE y de la UGT. Los documentos conservados tanto en su archivo como en su biblioteca han sido claves para reconstruir la relación de nuestro protagonista con el partido socialista, así como la carrera desarrollada dentro de las instituciones políticas y sanitarias surgidas durante el exilio republicano. Por otro lado, para entender otros aspectos de la vida de Aurelio Almagro ha sido necesario el estudio de la documentación existente en archivos tan importantes como el Archivo General de la Administración (AGA), el Archivo Carlos Esplá y la Biblioteca Virtual Cervantes y el Archivo del Congreso de los Diputados.

Por último, para dotar de cierta personalidad el relato que nos disponemos a presentar, son cruciales los datos aportados por la biznieta de Aurelio Almagro Gracia, Guadalupe de la Vega Almagro quien pertenece a los descendientes de nuestro protagonista que como veremos se mantuvieron en España y no vivieron el camino de exilio. Aunque la información recopilada de este testimonio no es muy extensa ya que esta rama familiar no vivió los sucesos del exilio y la vida de la familia en México, debemos agradecer su amabilidad y colaboración porque sin duda alguna los datos aportados nos permiten analizar de una manera más personal e íntima la trayectoria de Aurelio Almagro.

\section{2- AURELIO ALMAGRO GRACIA: MÉDICO, POLÍTICO Y MASÓN}

Aurelio Almagro Gracia nació el 10 de octubre de 1881 en Zaragoza y creció en el seno de una familia de clase media que se asentó en Cuenca a principios de 1890. Tras superar los estudios de bachillerato en el instituto de la ciudad, Aurelio regresó a Zaragoza accediendo a la Universidad y cursando la carrera de medicina en los primeros años del siglo $\mathrm{XX}^{2}$. Poco

casi 200 diputados que representaron a Andalucía en la Segunda República. Entre ellos, incluimos a Aurelio Almagro, elegido diputado por la provincia de Granada en 1936, una situación anecdótica que posteriormente analizaremos. L. Álvarez Rey (2009).

2. En el Archivo Histórico Nacional (AHN) se conserva el expediente académico de bachillerato de Aurelio Almagro. AHN, Universidades, Serie 7152, Expediente n. ${ }^{\circ} 4$. Expediente para la expedición del título de bachiller de Aurelio Almagro Gracia, natural de Zaragoza, alumno del Instituto de Cuenca, 10 de mayo de 1897. Respecto a su etapa universitaria, su expediente académico se conserva en el Archivo de la Universidad de Zaragoza (AUZ), Escuela Normal de Maestros de Zaragoza, Expediente 4-a-2-1. Expedientes académicos, 1882-1996. 
después de licenciarse, en la década de 1910, ejerció como médico mutualista de la Sociedad Obrera La Fraternal en la provincia de Cuenca ${ }^{3}$. Además, tomó la plaza de médico titular en la Beneficencia Municipal de Cuenca siéndole asignada la demarcación de la serranía del Campichuelo próxima a la capital ${ }^{4}$.

Gracias a su profesión Aurelio Almagro logró cierta popularidad entre la población de Cuenca lo que provocó el interés de los grupos políticos de la ciudad y de la provincia. Sin embargo, no fue hasta 1916 cuando Almagro decidió formar parte de uno de ellos: la Sociedad Obrera La Aurora, la cual estaba formada por jóvenes socialistas de la ciudad de Cuenca. Dos años después de su ingreso, en 1918, el periódico La Lucha anunciaba la formación de la Agrupación Socialista de Cuenca que estaba liderada por Aurelio Almagro, Juan Giménez de Aguilar y Crédulo Marcelino Escobar. Dicha organización alcanzó un mayor impulso con la llegada del conocido Rodolfo Llopis, conformándose así el grupo principal de los que estarían llamados a ser los protagonistas del socialismo conquense durante la Segunda República 5 .

En la década de 1920, además de participar en la vida política de Cuenca, Aurelio Almagro formó parte de algunos periódicos de la ciudad: el Progreso Conquense del que fue director a partir de 1921, El Deporte, Cuenca Sanitaria y Electra ${ }^{6}$. Por otro lado, a principios de 1928 Aurelio Almagro se inició en la masonería formando parte de la logia Ibérica $N .^{\circ} 7$

3. La Sociedad Obrera La Fraternal constituida el 27 de abril de 1903 con el nombre de Sociedad Benéfico-Obrera de Socorros Mutuos está considerada la primera organización obrera de Cuenca y cumplía una triple finalidad: benéfica, filantrópica y cultural. Á. L. López Villaverde, (1997), 118.

4. La asistencia sanitaria de la Beneficencia Municipal en la capital conquense de la época contaba con tres médicos titulares, cuatro farmacéuticos y cuatro practicantes. A todos ellos, incluido Aurelio Almagro, se les atribuyó el papel de socorrer las enfermedades accidentales, trasladar a los pobres y proporcionarles atención en su hogar, tanto en la capital como en la provincia. La única referencia sobre este organismo la encontramos en A. González García (2016), 228-270.

5. La Sociedad Obrera La Aurora fundada el 18 de julio de 1914 aparece como el máximo exponente del asociacionismo obrero de Cuenca entre las décadas de 1910 y 1920. Se trataba de una federación de sociedades encargada de estudiar las condiciones laborales y ofrecer una bolsa de trabajo que incluía a los distintos parados de la capital. Con el paso de los años su actuación fue monopolizada por miembros del PSOE y la UGT, expandiendo su actuación a través de la prensa con la edición de dos periódicos: Vida Obrera y La Lucha. Á. L. LóPez VillaVerde, (1997), 119-121.

6. La presencia de Aurelio Almagro en estos periódicos y la historia de los mismos ha sido recogida por el estudio de Á. L. López Villaverde e I. Sánchez Sánchez (1988). 
de Madrid con el nombre simbólico de Moncayo. Aunque no hemos podido localizar el registro de Aurelio Almagro en el taller masónico Triángulo Electra, el más importante de la región manchega, debemos suponer que Aurelio Almagro perteneció al mismo, ya que, como hemos mencionado formó parte en 1930 del periódico Electra, el cual estaba vinculado con dicho grupo masónico?

En 1930 en plena decadencia de la monarquía de Alfonso XIII la Agrupación Socialista de Cuenca había duplicado su militancia y contaba con una enorme base social, presentándose como un firme oponente del conservadurismo tradicional gracias a la reorganización llevada a cabo a finales de la década de 1920 por parte de Rodolfo Llopis y Aurelio Almagro. Sin embargo, pese a la efervescencia del PSOE, la situación de las fuerzas de izquierdas en Cuenca era muy inestable debido principalmente a la falta de acuerdos entre republicanos y socialistas. Ante esta situación no es de extrañar que, en las elecciones municipales del 12 de abril de 1931, los grupos monárquicos obtuvieran la victoria absoluta en la mayoría de pueblos de la provincia ${ }^{8}$.

Pese a los resultados electorales, en los días posteriores y a raíz de los acontecimientos ocurridos a nivel nacional, la ciudad de Cuenca fue testigo de las celebraciones y festejos de gran parte de la población ante la llegada de la República y el fin de la monarquía. Para impedir que hubiera altercados contra las autoridades locales aun monárquicas los grupos políticos de izquierda decidieron apaciguar las celebraciones hasta que se formará el nuevo gobierno municipal. El encargado de mantener la situación fue Aurelio Almagro Gracia quien tomó posesión del cargo de gobernador civil en nombre de las organizaciones de izquierdas el día 17 de abril de 1931. El líder socialista ostentó esta responsabilidad de manera excepcional, ya que, tan solo tres días después, el Boletín Oficial de la Provincia de Cuenca anunciaba la toma de posesión del nuevo gobernador, Manuel García-Rodrigo 9 .

7. El Triángulo Electra dependía desde 1925 de la logia madrileña Ibérica $N .^{\circ} 7$, que, a su vez, pertenecía a la Gran Logia Regional del Centro, una de las siete grandes logias regionales en que se organizaba el Gran Oriente Español. Dicha asociación fue fundada por Rodolfo Llopis y agrupó a los principales dirigentes socialistas y republicanos de la provincia de Cuenca e incluso algunos miembros de la CNT. Ver más detalles de la masonería conquense en Á. L. López Villaverde (1997), 141-146 y Á. L. López Villaverde y Á. R. del Valle Calzado, (1990).

8. Para un análisis completo y profundo sobre los procesos electorales de la Segunda República en Cuenca, véase el trabajo de M. Á. OrTegA, (1987).

9. La proclamación de la Segunda República y las celebraciones llevadas a cabo por las fuerzas de izquierdas, así como el brevísimo cargo de gobernador civil de Aurelio 
Tras la proclamación de la República la conjunción republicano-socialista lograría organizarse en la provincia de Cuenca, lo que permitió que en las elecciones constituyentes de junio de 1931 las fuerzas de izquierdas contaran con cierta representación. Aunque los resultados electorales no fueron muy positivos, entre los candidatos electos estaba Aurelio Almagro Gracia quien había logrado un total de 27.008 votos, convirtiéndose en el único socialista elegido y a su vez en el primer diputado del PSOE en la historia de Cuenca ${ }^{10}$.

Según quedó recogido en las actas del Congreso, Aurelio Almagro declaró su alta como diputado el 5 de julio de 1931, realizando la promesa de su cargo el 27 de julio de $1931^{11}$. La actuación de Aurelio Almagro en el Congreso de los Diputados durante el primer bienio republicano fue secundaria y casi representativa, participando únicamente como vocal titular en la Comisión de Gobernación. A partir de los datos aportados por el historiador Leandro Álvarez Rey conocemos que Almagro se mudó a la calle Torrecilla del Leal n. ${ }^{\circ} 2$ de Madrid. Su traslado a la capital impidió su participación en activo en la Agrupación Socialista de Cuenca lo que provocó a su vez su renuncia como miembro del grupo socialista, una petición que fue denegada con rotundidad por sus compañeros, al entender que la posición en el Congreso de Aurelio Almagro podría traer beneficios a la región ${ }^{12}$.

Su estancia en Madrid duró hasta el otoño de 1933. La convocatoria de nuevas elecciones generales provocó la baja como diputado de Aurelio Almagro el 9 de octubre de 1933 y esto a su vez el regreso a Cuenca para preparar la nueva cita electoral. En esta ocasión y debido al fracaso generalizado de republicanos y socialistas en toda España, el exdiputado no consiguió ser reelegido, por lo que durante el segundo bienio de la República Aurelio Almagro estuvo alejado del centro político, dedicándose con especial atención a su verdadera vocación: la medicina y el auxilio de los más necesitados dentro de la Beneficencia Municipal de Cuenca.

Esta situación se mantuvo hasta finales de 1935 cuando la convocatoria de nuevas elecciones generales para febrero de 1936 situó de nuevo a Aurelio

Almagro se recoge en el periódico Electra N $^{\circ}$ 36, 23 de abril de 1931. Para ver más detalles de estos sucesos véase Á. L. López VillaVerde (1997), 180.

10. Todos los detalles sobre las elecciones constituyentes de 1931 en Cuenca véase en Á. L. López Villaverde (1997), 225-243.

11. Archivo del Congreso de los Diputados (ACD), Documentación electoral, Serie 137, Exp. n. ${ }^{\circ}$ 18. Credencial n. ${ }^{\circ} 77$.

12. L. Álvarez Rey, (2009), 271. 


\section{Imagen 1}

Diputados electos en las elecciones constituyentes de junio de 1931 en la provincia de Cuenca. Aurelio Almagro Gracia, esquina inferior izquierda.
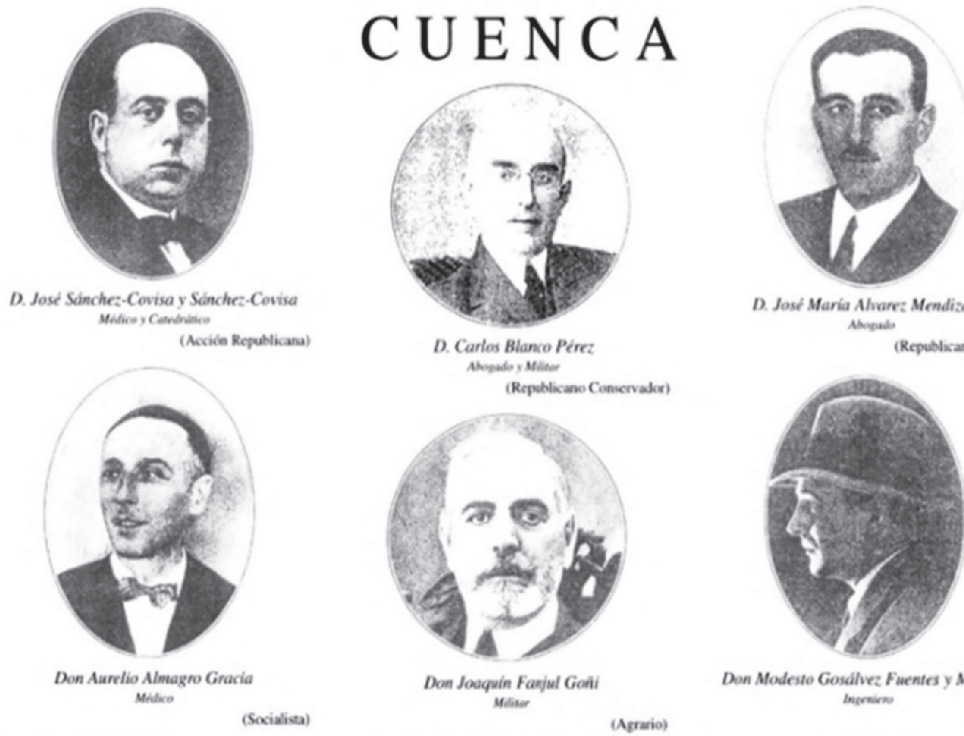

D. Carles Blanco Pérez thendey Minu

D. Josi Maria Aharez Mendisábal Ahyou

(Republicano Radical)

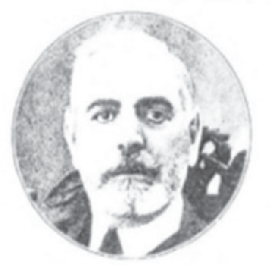

Don Jodquin Farjul Goili

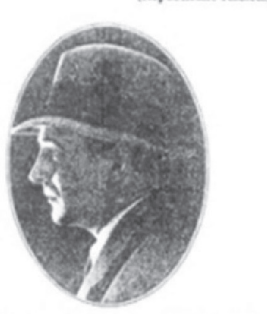

Don Modesto Gosalvez Fuentes y Manresa

(Azrario)

A Agraioi

Contes Constituyentes 1931. Madrid, Rivas, 1932. Pág. 24

Fuente: Á. L. López Villaverde (1997), 238.

Almagro Gracia en la primera línea de la política provincial de Cuenca. En esta ocasión la formación del Frente Popular propició la aparición de nuevas candidaturas conjuntas entre socialistas y republicanos y en la provincia de Cuenca concurrían con cuatro aspirantes: dos correspondientes a Izquierda Republicana y dos al PSOE, Aurelio Almagro y el abogado Luis García Cubertoret. Pese a su destacado apoyo social, sobre todo entre las clases más necesitadas, y su involucración en la campaña electoral, destacando la intervención de Aurelio Almagro el 15 de diciembre de 1935 en el mitin organizado por el PSOE en el Teatro de Cervantes de Cuenca, el candidato socialista estaba entre los no elegidos y en la circunscripción de Cuenca venció de manera contundente la candidatura derechista ${ }^{13}$.

Pese a la derrota socialista en Cuenca, los resultados de las elecciones de febrero fueron impugnados, teniendo que recurrir a una segunda vuelta

13. Ver todos los detalles de las elecciones de 1936 en Cuenca en Á. L. Lóp ez ViLAVerde (1997), 262-279. 
en mayo, donde se impuso la candidatura del Frente Popular. Esta región no fue la única en repetir las elecciones, en Granada se produjo la misma situación. Mencionamos el caso de esta provincia andaluza, ya que la comisión ejecutiva nacional del PSOE propuso a los comités del Frente Popular de ambas provincias un intercambio de candidatos para la repetición de las elecciones. La proposición consistía en que el socialista Aurelio Almagro Gracia se presentaba por Granada mientras que el republicano Emilio Martínez Jerez de Unión Republicana por Cuenca. Tras algunas quejas por parte de los organismos republicanos de Granada, el 22 de abril de 1936 se aceptó la propuesta. Sin embargo, la proclamación por Cuenca de Martínez Jerez no fue aceptada por la Junta provincial del censo mientras que sí lo fue la de Aurelio Almagro por Granada que, en las elecciones de mayo obtuvo 207.215 votos, resultando el sexto de los trece diputados electos en aquellas elecciones ${ }^{14}$. De esta manera, adscrito a la minoría socialista de Granada, Aurelio Almagro volvía a ser elegido como diputado, dándose de alta en su cargo el 8 de mayo de 1936 y realizando la promesa del mismo el 22 de mayo $^{15}$. Aunque como diputado tuvo que volver a Madrid, donde residiría en la calle de Alcalá n. $^{\circ}$ 138, Aurelio Almagro apenas intervino en las sesiones y debates parlamentarios y en esta ocasión sí mantuvo la relación con su trabajo como médico de la beneficencia y la agrupación socialista de Cuenca.

El Golpe de Estado Militar del 18 julio de 1936 y el inicio de la Guerra Civil supuso una ruptura en la evolución política de Aurelio Almagro, quien, con una edad bastante madura (44 años), se enfrentaba al mayor desafío de su vida. Según las breves referencias aportadas por Leandro Álvarez Rey, durante julio de 1936 y enero de 1938 Aurelio Almagro permaneció en zona republicana encargándose de la organización de los servicios médicos del Ejército voluntario de la República en varias zonas y frentes, principalmente en los hospitales de Cuenca y Madrid ${ }^{16}$.

Durante el transcurso de la guerra Aurelio Almagro se mantuvo fiel a la República y a su cargo como diputado. Participó como vocal titular en las Comisiones de Trabajo y Asistencia Social y como vocal suplente a las

14. El complicado asunto de las actas y el intercambio de candidatos entre la provincia de Cuenca y Granada, así como la discusión de las actas en la provincia de Cuenca en las elecciones de febrero y su repetición en mayo se puede estudiar con profundidad en Á. L. López Villaverde (1997), 289-331.

15. ACD, Documentación electoral, Serie 141, Exp. n. ${ }^{\circ} 20$. Credencial n. $^{\circ} 482$.

16. L. Álvarez Rey (2009), 272. 
Comisiones de Instrucción Pública, Tribunal de Cuentas y Presupuestos. También asistió a varias sesiones parlamentarias, entre las que destacan las celebradas en Valencia a comienzos de octubre de 1937 y en Sabadell un año después. Como miembro del PSOE en el Congreso republicano y fiel representante de los ideales socialistas participó en las diferentes reuniones del Grupo Parlamentario Socialista (Minoría Parlamentaria Socialista) de enero y septiembre de 1938, ambas celebradas en Barcelona ${ }^{17}$.

Aunque Aurelio Almagro no figura en el listado de los diputados asistentes a la última reunión del Congreso republicano celebrada en territorio español, concretamente en el Castillo de Figueras en febrero de 1939, este diputado socialista si formaba parte de la columna de republicanos que intentaron cruzar la frontera francesa a finales de febrero de dicho año. En aquel momento, Aurelio y su familia, de la que hablaremos posteriormente, formaron parte del millar de políticos, funcionarios, miembros del ejército y civiles, todos ellos relacionados con el gobierno republicano y sus instituciones que no tuvieron otro remedio que huir ante el avance sublevado y la incipiente derrota de la República.

\section{LA LUCHA CONTINUA: MEDICINA Y SOCIALISMO EN EL EXILIO}

Las cuestiones que motivaron el exilio de Aurelio Almagro Gracia son obvias, desde su juventud había defendido los ideales del movimiento obrero, participando y construyendo el PSOE de la provincia de Cuenca, un tarea intelectual y política que le llevó a conseguir la representación parlamentaria en las cortes republicanas de 1931 y 1936. Por si no fuera poca su pertenencia al socialismo español, considerado uno de los enemigos del régimen franquista, Aurelio Almagro era miembro de la masonería y además había formado parte del ejército republicano durante la Guerra Civil. Por todo ello, Aurelio Almagro tenía razones suficientes para temer por su vida y por la de sus familiares, de ahí que decidiera marchar al exilio iniciando una vida totalmente nueva que como veremos no será nada fácil ${ }^{18}$.

17. Su presencia tanto en las reuniones del Congreso como en las del Grupo Parlamentario Socialista aparece en Fundación Pablo Iglesias (FPI), Archivo Histórico (AH), 18-7. Actas de las reuniones celebradas por el Grupo Parlamentario Socialista (Minoría Parlamentaria Socialista) del 15/3/1936 al 1/2/1939.

18. No tenemos constancia de cuándo y cómo fue la condena que debió imponerle en la postguerra el Tribunal Especial para la Represión de la Masonería y el Comunismo. Existen algunos datos acerca de su procesamiento por el Tribunal Nacional de Res- 
El proceso del exilio de Aurelio Almagro Gracia, al igual que el de miles de republicanos exiliados, le obligó a desplegar nuevas habilidades vitales, a afilar su capacidad de adaptación y reconstruir su persona, algo incompatible con la evaluación de los exilios como algo fijo y, mucho menos, como procesos de final predecible. Todo ello se entiende por una simple cuestión, los exiliados no eran personas distintas en esencia a las que eran cuando iniciaron el exilio, pero sí acabaron siendo personas nuevas, reconstruidas y formadas por las nuevas circunstancias. En el caso de Aurelio Almagro veremos que, pese a su edad avanzada, las tragedias vividas y la nueva vida en un país como México, mantendrá viva su esencia, apostando por la legitimidad de la República, la lucha los ideales democráticos, la defensa del socialismo, la fidelidad a su partido y la necesidad de ayudar a los más necesitados. Una incansable lucha que le llevará a formar parte de diferentes organismos republicanos del exilio y con ello a compartir su experiencia con la de centenares de exiliados.

\subsection{De Francia a México: familia y enfermedad}

El proceso de exilio de Aurelio Almagro Gracia comienza a finales de febrero de 1939 cuando junto a su mujer y su hija cruzan la frontera francesa. Estos momentos estuvieron marcados por el miedo y la incertidumbre, ya que atrás dejaba toda una vida y lo más importante a cuatro hijos. Según hemos podido conocer gracias al relato aportado por la biznieta de nuestro protagonista, Guadalupe Almagro, Aurelio estaba casado con Amalia Tello Zueco, natural de Cuenca, con quién compartía cinco hijos: por un lado, Mariano, Jorge y Aurelio, quienes fueron detenidos y juzgados por las autoridades franquistas tras el final de la Guerra y afortunadamente sobrevivieron al encarcelamiento, pasando el resto de sus vidas en Cuenca; por otro lado, Luis, el menor de la familia, fue depurado como maestro nacional y como veremos posteriormente consiguió huir a México tras pasar un tiempo encarcelado; por último, y más importante, su hija Amalia,

ponsabilidades Políticas, a raíz de las diligencias abiertas por la Sala de Instrucción 2. ${ }^{a}$ de la Audiencia Provincial de Cuenca con fecha 23 de julio de 1945 (número de Expediente 3.439). La tramitación de su proceso fue muy rápida pues una semana después, el 3 de agosto de 1945, la Comisión Liquidadora de Responsabilidades Políticas decidió el sobreseimiento conforme al artículo $8 .^{\circ}$ de la Ley de 9 de febrero de 1942, que eximía de sanción a los "responsables políticos" cuyo patrimonio no fuera superior a las 25.000 pesetas. Archivo General de la Administración (AGA), sección Justicia, Tribunal Nacional de Responsabilidades Políticas, leg. 75/00466. 
quien será junto a su madre, quienes acompañarán a Aurelio Almagro en el exilio, además de su esposo Mario Lagunilla Leça odontólogo madrileño ${ }^{19}$.

Lamentablemente no contamos con los datos suficientes para reconstruir el recorrido de Aurelio Almagro y su familia por Francia. Lo poco que conocemos es que la familia Almagro Tello fue internada en uno de los campos de refugiados habilitados por las autoridades francesas en el Pirineo francés. Unos centros de internamiento que más que refugios se convirtieron en cárceles improvisadas para los republicanos y donde las condiciones sanitarias y el trato del Gobierno francés brilló por su ausencia. Esta circunstancia provocó la muerte y la enfermedad de miles de hombres, mujeres y niños, entre ellos Aurelio y su mujer, quienes enfermaron de gravedad durante las semanas de cautiverio. Aunque el internamiento de la familia Almagro Tello fue breve, la condición de político de Aurelio le permitió encontrar refugio en las cercanías de la ciudad de Toulouse, las consecuencias fueron funestas: su mujer Amalia nunca superó la enfermedad respiratoria contraída y fallecerá en 1943.

De la misma manera que Aurelio Almagro y su familia lograron encontrar refugio en Toulouse también fueron afortunados al conseguir pasaje en uno de los barcos fletados por el Gobierno republicano rumbo a Latinoamérica. Concretamente en el conocido buque Sinaia que marchó a México el 25 de mayo de 1939 con un total de 1.599 refugiados a bordo. La travesía hasta el puerto de la ciudad de Veracruz duró 19 días, siendo el 13 de junio el día en que Aurelio Almagro puso pie en México, una tierra que se convirtió en su país de acogida y su nuevo hogar hasta el final de sus días ${ }^{20}$. Tras su llegada tanto Aurelio como su mujer y su hija fueron inscritos en el Registro Nacional de Extranjeros de México y se les realizó un visado especial que recoge la condición de asilo político de todos los miembros de la familia, así como varios datos de los mismos: sobre Amalia Tello Zueco debemos destacar que nació el 10 de julio de 1886 en Cuenca, era ama de casa y en el reverso de su registro aparece la cancelación del asilo político por fallecimiento el 5 de marzo de 1943. Por su parte, la hija del matrimonio, Amalia Almagro Tello, aparece como

19. Luis Almagro Tello, maestro nacional en Cuenca, fue depurado por el Ministerio de Educación Nacional, siendo incapacitado para el cargo de su profesión y encarcelado durante dos años. AGA, Ministerio de Educación Nacional, Expedientes de depuración de maestros nacionales, leg. 32/12568, 1936-1942.

20. El nombre de Aurelio Almagro Gracia y su familia aparecen en el listado de pasajeros del Sinaia, cuya copia digital está disponible en la FPI, AH, Exilio, Barcos, Lista de pasajeros del Sinaia (México), fol. 32. 
una joven de 31 años, nacida el 18 de enero de 1907, ama de casa, casada $\mathrm{y}$ residente en Beteta (Cuenca) ${ }^{21}$.

Los primeros momentos en México fueron de enorme complejidad para Aurelio Almagro y su familia, la edad, la delicada salud de su mujer, la falta de recursos y la dificultad para adaptarse a un nuevo país obligaron a nuestro protagonista, al igual que a otros miles de exiliados republicanos, a acudir a los organismos de ayuda establecidos por el Gobierno de la República. Tanto Aurelio como su hija se beneficiaron de una pequeña ayuda de 150 pesos mexicanos aportada por el Comité Técnico de Ayuda a los Republicanos Españoles (CTARE), dependiente del Servicio de Emigración de Republicanos Españoles (SERE)22. El 28 de febrero de 1940 la Junta de Auxilio a los Republicanos Españoles (JARE) acordaba auxiliar a Aurelio Almagro con 500 pesos, remarcando que se trataba de un pago único y definitivo ${ }^{23}$. No obstante, la condición de diputado iba a beneficiar de nuevo a nuestro protagonista y en el mes de abril se le facilitó un nuevo socorro de 250 pesos $^{24}$.

\subsection{El Servicio Médico-Farmacéutico de la JARE}

En el mes de febrero de 1939, poco antes de finalizar la Guerra Civil, el presidente del Gobierno republicano Juan Negrín creó en París un organismo para ayudar a los españoles que tras el avance de las tropas nacionalistas en Cataluña abandonaron el país. Se trataba del Servicio de Emigración (o de Evacuación) de Republicanos Españoles (SERE) cuyos fines eran ayudar a los refugiados en Francia, trasladarlos a otros países y proveerlos de medios de subsistencia, trabajo, asistencia médica y educación. Sin embargo, gran parte de los fondos del SERE, transportados a México en el conocido yate Vita, cayeron fortuitamente en manos de Indalecio Prieto. Este, ferozmente

21. Dichos documentos están localizados en el fondo de Secretaría de Gobernación de México y el Departamento de Migración del Archivo General de la Nación de México y existe una copia digital de los mismos en el Archivo General de la Administración y a su vez están disponibles en el portal Movimientos Migratorios Iberoamericanos perteneciente al Ministerio de Cultura y Deporte. Signatura de la copia digital, AGA, RIEM, 006, 108. Ficha personal de Aurelio Almagro García, 13/6/1939.

22. Los expedientes de Aurelio Almagro y Amalia Almagro Tello se encuentran disponibles en la Biblioteca Nacional de Antropología e Historia (BNAH), México, Fondo CTARE, Expedientes Personales, carpeta 0239 y 3494, respectivamente.

23. Archivo Carlos Esplá, Libros de Actas de la JARE, Libro n. ${ }^{\circ}$ 1, Acta n. ${ }^{\circ} 39,28 / 2 / 1940$.

24. Archivo Carlos Esplá, Libros de Actas de la JARE, Libro n. ${ }^{\circ}$ 1, Acta n. ${ }^{\circ}$ 57, 12/4/1940. 


\section{Imagen 2}

Visado Especial como asilado político de Aurelio Almagro Gracia. Registro Nacional de Extranjeros, Ciudad de México, 13 de junio de 1939.

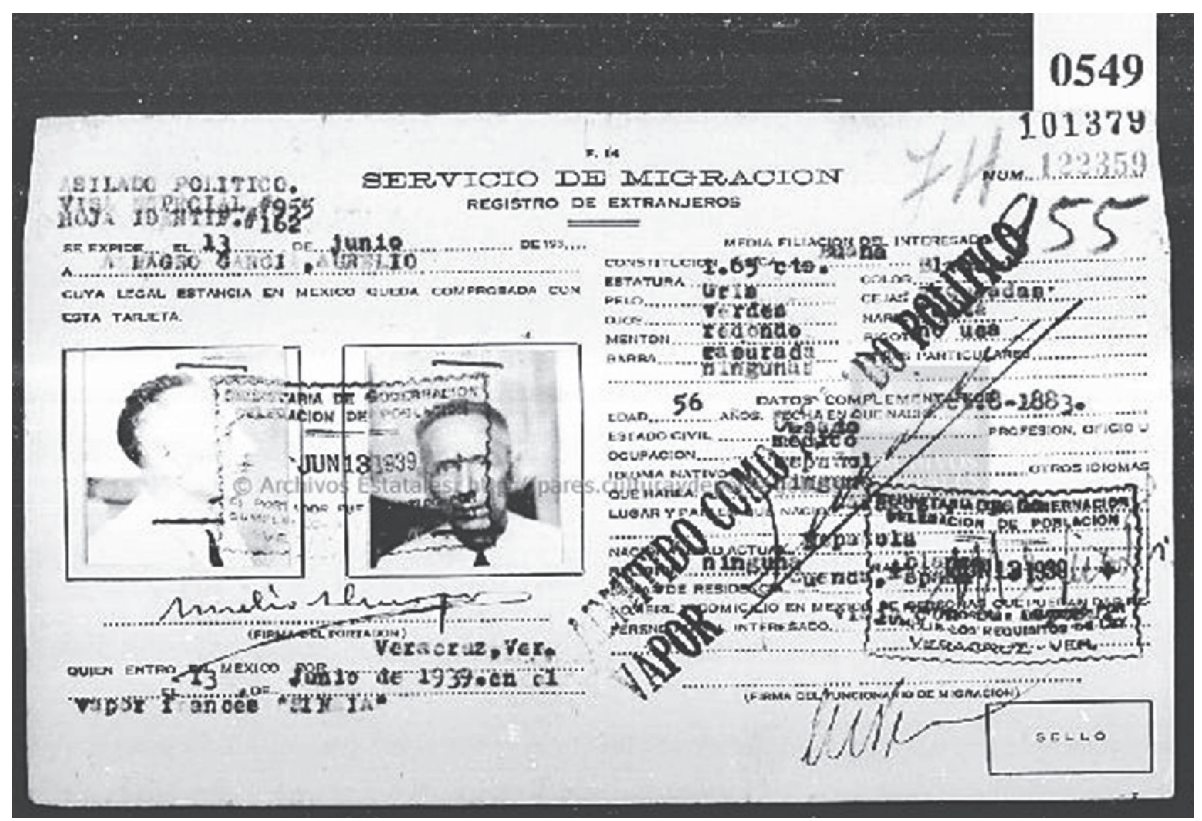

Fuente: Portal Movimientos Migratorios Iberoamericanos.

enemistado con Negrín, retuvo la mercancía y aprovechó la circunstancia en su beneficio. Tras varios y fracasados intentos de concordia, el 26 de julio de 1939 los miembros de la Diputación Permanente de las Cortes, hábilmente manejados por Prieto, crearon la Junta de Auxilio a los Refugiados Españoles (JARE) con el fin de administrar dicho caudal y auxiliar a los exiliados españoles, logrando a su vez el apoyo de los mismos frente a Negrín ${ }^{25}$.

Para contrarrestar esta estrategia el SERE constituyó en mayo de 1939 en México el Comité Técnico de Ayuda a los Refugiados Españoles (CTA-

25. Para conocer de manera extensa la historia de estos organismos y su rivalidad es de obligada necesidad la consulta de la bibliografía existente al respecto, tanto la que trata la vida de sus inspiradores, para Juan Negrín, véase entre otros E. Moradiellos (2006) y para Indalecio Prieto, el completísimo estudio de O. Cabezas (2005); como las innovadoras y recientes investigaciones sobre los propios organismos: A. MATEOS (2009), Á. Herrerín (2007) y sobre todo el trabajo de A. Velázquez Hernández (2014), donde se explora de manera exhaustiva cada una de las instituciones mencionadas. 
$\mathrm{RE})$ que contaba con una sección dedicada al auxilio de enfermos y heridos de guerra ${ }^{26}$. A mediados de 1940, con gran parte de los fondos agotados, se suspendieron la mayoría de las ayudas. Entonces y en previsión de la llegada a México de miles de españoles, la JARE decidió hacerse cargo de su asistencia socio-sanitaria. Para ello la delegación liderada por Indalecio Prieto acordó de 30 de abril de 1940 organizar un comité de socorros, un servicio médico y farmacéutico gratuito y un plan de educación junto a la construcción de albergues y comedores. A raíz de esta propuesta nacía el Servicio Médico-Farmacéutico de la JARE que desde mediados de 1940 asumió la asistencia socio-sanitaria y funcionó con acierto, aunque sometido a diversas presiones económicas, hasta bien entrado el año 1942. Los beneficiarios de la entidad fueron españoles con nulos o reducidos recursos económicos, incapaces de sufragar la asistencia sanitaria en el país latino. Gracias a este servicio se auxilió alrededor de 5.000 exiliados en Ciudad de México, sin contar los que vivían fuera de la capital que también fueron a atendidos ${ }^{27}$.

Una de las tareas más importantes de este organismo fue la asistencia domiciliaria gratuita que comenzó a funcionar a partir del 30 de mayo de 1940 gracias al trabajo de los médicos Roberto Escribano Iglesias y Aurelio Almagro Gracia, quienes iniciaron su actividad como médicos de cabecera dos días después bajo la dirección del médico personal de Indalecio Prieto, Rafael Fraile. De esta manera Aurelio Almagro se integraba en el servicio de asistencia domiciliaria a los refugiados españoles asignándosele la retribución mensual de 250 pesos, los costes de transporte e incluso un despacho particular para sus consultas ${ }^{28}$. Durante todo el año de 1940 Aurelio Almagro trabajó como médico domiciliario de la JARE encargándose también de la asistencia a los miembros de la agrupación de inválidos y mutilados de la República, un trabajo que aliviaría los problemas económicos de la familia Almagro Tello en los primeros meses de exilio ${ }^{29}$. Además, para estos momentos todos los miembros de la familia se habían establecido en una vivienda de la Colina Nueva Santa María de Ciudad de México, incluido el marido de su hija Amalia, Mario Lagunilla Leça, especialista

26. Sobre la filial en México del SERE, es decir, el CTARE, apenas hay referencias salvo las muy escasas que se incluyen en una biografía de su presidente, José Puche. Véase J. L. Abellán y M. F. Mancebo Alonso (1989) y la obra de M. Ordóñez Alonso (1997).

27. Véase para más detalles sobre este organismo, F. Girón y E. Barranco (2011), 159-181.

28. Archivo Carlos Esplá, Libros de Actas de la JARE, Libro n. ${ }^{\circ}$ 1, Acta n. ${ }^{\circ} 74,30 / 5 / 1940$.

29. Archivo Carlos Esplá, Libros de Actas de la JARE, Libro n. ${ }^{\circ} 1$, Acta n. ${ }^{\circ} 82,24 / 6 / 1940$. 
en odontología que trabajaba también de manera ocasional para la JARE.

Para noviembre de 1940 el servicio farmacéutico de la JARE ya disponía de farmacia, consultorios propios, un cuadro básico de especialistas, entre ellos Aurelio Almagro encargado de medicina general y pediatría ${ }^{30}$. Bajo la dirección de Alejandro Otero Fernández, prestigioso catedrático de Obstetricia de Granada y uno de los líderes socialistas afines a Indalecio Prieto, la asistencia sanitaria a los republicanos españoles en Ciudad de México permitió entre otras cuestiones: la atención a la maternidad en Instituciones sanitarias, la distribución de medicamentos a un coste aceptable y las intervenciones quirúrgicas por profesionales cualificados ${ }^{31}$. Sin embargo, la adjudicación de los puestos en este organismo e incluso la asistencia a los enfermos no estuvo exenta de clientelismo pues la pertenencia al PSOE y, en concreto, la afinidad con el grupo de Indalecio Prieto, constituyó una baza muy importante.

\subsection{La Benéfica Hispana}

Pese al buen funcionamiento de la JARE la desconfianza del gobierno mexicano hacia la gestión de los bienes de dicha institución precipitó su cierre y a primeros de 1941 comenzaron los procedimientos para su disolución. El gobierno del general Ávila Camacho anunció dicha noticia el 21 de enero de 1941 y para el 27 de noviembre de 1942 la JARE había sido sustituida por la Comisión Administradora del Fondo de Auxilio a los Refugiados Españoles (CAFARE), organismo que funcionó hasta 1946. El Servicio Médico-Farmacéutico fue suprimido el 31 de julio de 1942 junto a otros servicios como la Oficina de Socorros. Ante esta situación los médicos que ofrecían este servicio decidieron constituir una cooperativa: la Policlínica Española que aglutinó a los antiguos beneficiarios de la JARE. La nueva plataforma sanitaria no logró el mismo éxito y se vio obligada a fusionarse con la Cooperativa Española de Asistencia Médico

30. La mayoría de estos especialistas y colaboradores eran médicos reconocidos en la medicina española como Alejandro Otero Fernández, Manuel Rivas Cherif, Juan Solares Encinas o el mencionado Rafael Fraile Ruiz de Quevedo. La lista de médicos que colaboraron en la JARE en F. Girón y E. Barranco (2011), 165.

31. Entre el mes de mayo de 1940 y el 30 de enero de 1942, se atendieron un total de 2.088 casos, entre los cuales podemos destacar que 1.521 fueron consultas de medicina general, de las que 889 se realizaron en el consultorio y 632 a domicilio y los restantes 567 casos fueron consultas a especialistas. En estas atenciones se realizaron 115 radiografías, 37 operaciones y 13 partos F. Girón y E. BArRanco (2011), 159-181. 
Farmacéutica dando lugar a la Benéfica Hispana, Sociedad de Asistencia Médico Farmacéutica ${ }^{32}$.

El nacimiento de la Benéfica Hispana, que modificó de nuevo su nombre el 18 de julio de 1943 como Benéfica Hispana. Asociación Civil Mutualista, está vinculado a un pequeño grupo de médicos y especialistas sanitarios españoles, muchos mencionados anteriormente y quienes a su vez estaban estrechamente relacionados con el Círculo Cultural Pablo Iglesias, el organismo representante del ala moderada del PSOE de Ciudad de México liderada por Indalecio Prieto. La Junta Directiva estaba formado por Celestino García como presidente y Benjamín Cáceres como tesorero y estaban apoyados por una veintena de médicos españoles de importancia: el propio Aurelio Almagro Gracia, los mencionados Alejandro Otero, Roberto Cherif, Roberto Escribano y Mario Lagunilla y como director médico de esta asociación, el prestigioso Joaquín D'Harcourt ${ }^{33}$.

32. A diferencia de las instituciones de auxilio de refugiados españoles mencionadas anteriormente, la Benéfica Hispana carece de un trabajo de investigación sobre la creación, evolución y funcionamiento de la misma. Además, la producción documental de la Benéfica Hispana se encuentra dispersa en diferentes archivos históricos. Por un lado, la Fundación Pablo Iglesias cuenta con una extensa relación de documentos que se encuentran localizados mayormente en el archivo personal de Julián Borderas Pallaruelo, una de las figuras principales del socialismo prietista y miembro de la Benéfica Hispana en cargos de administración. Este archivo cuenta con una centena de documentos que van desde los estatutos y reglamentos, las actas de las asambleas, impresos de suscripción, boletines, folletos, memorias, informes y balances económicos. Por otro lado, en el Archivo General de la Administración como en el Archivo Carlos Esplá y la Biblioteca Virtual Cervantes se localizan varios documentos de importancia, que posteriormente mencionaremos. Pese a toda la documentación producida por la Benéfica Hispana, su estudio y análisis se escapa de nuestro objetivo principal, ya que, como veremos a continuación, Aurelio Almagro Gracia formó parte de este organismo entre 1943 y 1947, unos años en los que la documentación es bastante escasa, en comparación con la década de 1950, cuando esta institución alcanza su consolidación y funcionamiento óptimo.

33. Los primeros momentos de la Benéfica Hispana y su evolución se pueden ver en Historia y Significación de la Benéfica Hispana, un pequeño relato sobre el nacimiento y desarrollo de la Benéfica Hispana realizado por el periódico Adelante, perteneciente a la Agrupación Socialista Española de México. FPI, Biblioteca, FBB 266, Historia y Significación de la Benéfica Hispana, Impresiones modernas, México, D. F. 1954. Además, la propia Benéfica Hispana editó un pequeño boletín sobre el nacimiento de la institución. Véase para estos primeros momentos: AGA, Fondo JARE, Caja M-323,

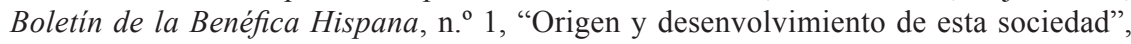
México, enero de 1945. 
El objetivo principal de sus fundadores fue suplir la falta de financiación. La JARE, disuelta por el gobierno mexicano, había dejado de pagar las cuotas de los afiliados siendo prácticamente imposible costear los gastos originados por la utilización de sanatorios y clínicas privadas. La solución ante este problema fue muy arriesgada y consistió en la adquisición de un edificio propio donde establecer un sanatorio y departamento de maternidad que permitiera la llegada de nuevos socios. El propósito se logró en septiembre de 1943 cuando se adquirió el edificio n. ${ }^{\circ} 58$ de la calle Marsella de Ciudad de México, un edificio de tres pisos donde el primero se destinaría al consultorio y a la administración, el segundo a quirófanos y el tercero a los servicios de maternidad ${ }^{34}$.

Una vez establecido el local, la Benéfica Hispana a principios de 1945 comenzó a publicar un boletín informativo para sus asociados con el título: Benéfica Hispana. Asociación Civil Mutualista. Medica General, Sanatorio, Maternidad, que sería publicado al menos hasta el mes de diciembre de 1951 a un ritmo de dos números por año ${ }^{35}$. Es en el primer boletín de la Asociación, fechado en enero de 1945, donde vemos la función y constitución de la Benéfica Hispana de manera más clara: ofrecer a los republicanos exiliados, una asistencia médica eficiente y digna dentro de las complicaciones económicas de los refugiados españoles. Un servicio médico que no iba destinado únicamente a los socios, los cuales contribuyen con sus cuotas, sino que también fueron beneficiarios muchos españoles y mexicanos no asociados. Para cumplir plenamente sus objetivos la Benéfica Hispana fue adquiriendo nuevos materiales, lo que permitió multiplicar su actividad: visita domiciliaria, diagnósticos (laboratorio, análisis clínicos, rayos X), consulta general, servicio quirúrgico, obstétrico y farmacéutico.

Durante la década de 1950 la Benéfica Hispana alcanzó su época de esplendor que se vio reflejado en la adquisición del Sanatorio Los Ángeles en la colonia Narvarte y el aumento de los asociados y los

34. Pese a la creación de un sanatorio propio, la Benéfica Hispana utilizará otras instituciones para sus servicios clínicos, de maternidad, farmacia, laboratorios y enterramientos: Sanatorio La Torre, Sanatorio Condesa, Maternidad Liverpool, Farmacias Mascarones, Velaverde y El Elefante, y la funeraria Gayosso. AGA, Fondo JARE, Caja M-323, Memoria, Benéfica Hispana, México, 1942-1943.

35. Hemos señalado el año 1951, porque es la fecha más tardía que tenemos documentada la existencia de este boletín, el cual se encuentra disponible en la Biblioteca Cervantes del Archivo Carlos Esplá, Benéfica Hispana. Revista Trimestral, México, D. F., año VII, n. ${ }^{\circ} 15$, diciembre de 1951. 
servicios prestados. La institución comienza a decaer en torno a 1963 cuando los problemas económicos salen a la luz a través de una huelga del personal médico. La última referencia que tenemos sobre este organismo es en 1966, cuando el Consejo directivo informa a la Asamblea General Ordinaria sobre los problemas económicos e internos que arrastra la Benéfica Hispana, pero sin referencia alguna al cierre de la organización $^{36}$.

Respecto a la tarea de Aurelio Almagro Gracia dentro de la Benéfica Hispana no dictaba mucho de la que venía realizando anteriormente. Almagro estaba encargado de los casos de medicina general y pediatría, los cuales atendería tanto en los domicilios de los enfermos como en el consultorio. Su relación con esta institución duró desde 1943 a 1947 trabajando en un horario limitado de tres días por semana, ya que, la edad y los problemas de salud comenzaban a hacer mella en nuestro protagonista. Debido a estas cuestiones, a principios de 1947, Aurelio Almagro deja de formar parte directa de esta asociación y aparece como "médico honorario" realizando pequeñas consultas cuando era solicitado por algunos de los asociados.

Durante todo ese tiempo Aurelio Almagro había vivido una "montaña rusa" de situaciones personales. El 5 de marzo de 1943 había perdido a su fiel compañera, su mujer Amalia Tello, y sus problemas de salud habían derivado en una miocarditis que le impedía realizar su trabajo con tranquilidad. El vacío dejado por su esposa fue cubierto en cierta medida por una inesperada noticia, su hijo Luis, recluido en una cárcel franquista desde 1939, había logrado llegar a México a principios de marzo de 1945 tras ser auxiliado por la Comisión Administradora del Fondo de Auxilio a los Refugiados Españoles (CAFARE) que costeó el pasaje de Luis Almagro Tello desde la Habana a Ciudad de México. Por otro lado la situación económica de la familia mejoró a finales de la década de 1940, sobre todo la de su hija Amalia y el esposo de ella, Mario Lagunilla Leça, quien desarrolló una importante carrera como odontólogo en varios países de Latinoamérica ${ }^{37}$.

36. FPI, Biblioteca, FA 996, El Consejo Directivo de Benéfica Hispana, ACM informa a la Asamblea General Ordinaria, mayo de 1966.

37. En el Archivo General de la Administración se encuentra el expediente personal de Aurelio Almagro realizado por la Comisión Administradora del Fondo de Auxilio a los Refugiados Españoles (CAFARE) y que contiene que contiene varios documentos que dan testimonio de los datos personales mencionados. AGA, JARE, caja M-7, 128 12/03010. Expediente 20, Aurelio Almagro Gracia. 


\section{Imagen 3}

Vista del edificio de la Benéfica Hispana,

Ciudad de México, calle Marsella n. ${ }^{0}$ 58, agosto de 1947.

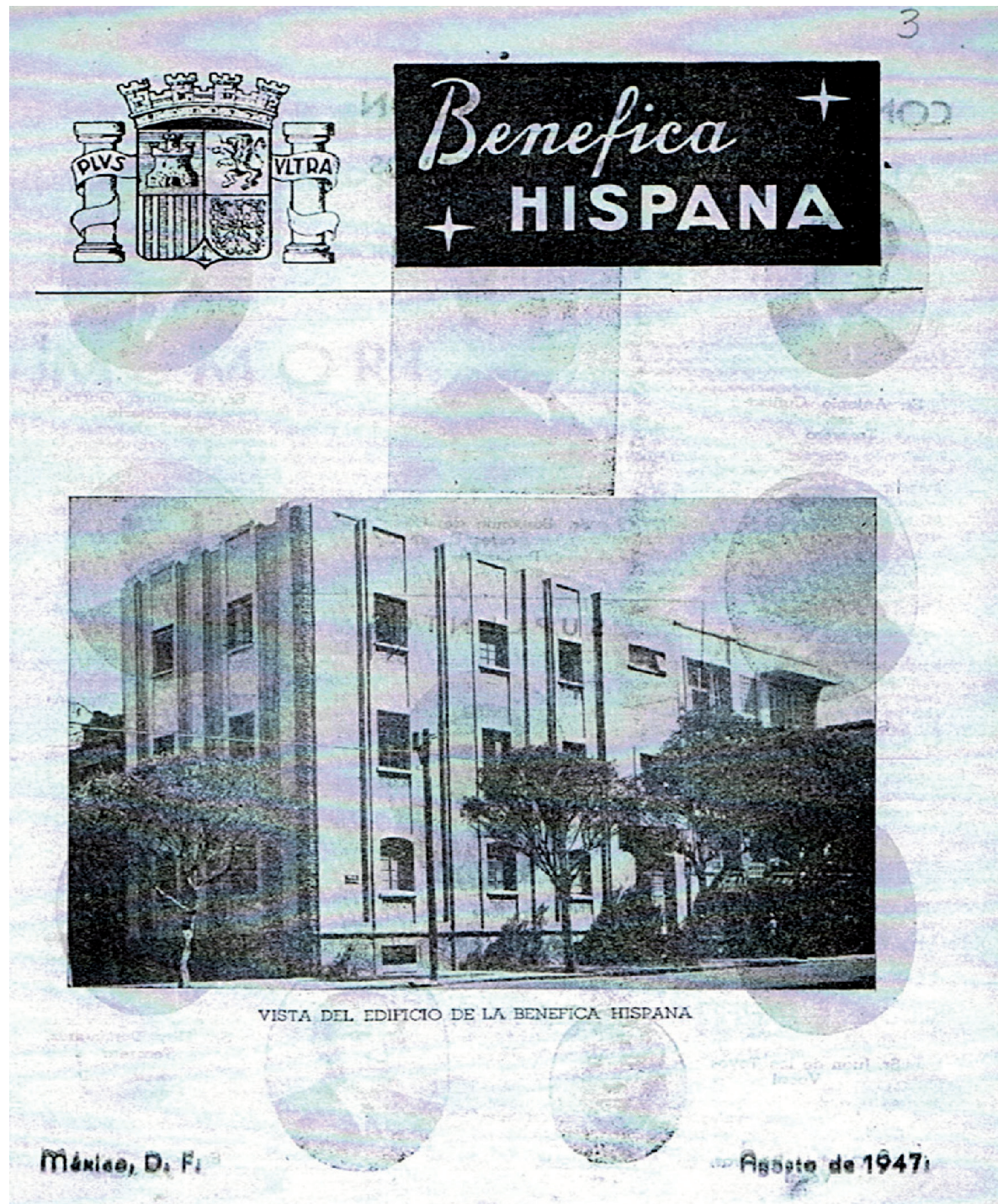

Fuente: Fundación Pablo Iglesias ${ }^{38}$.

38. FPI, Archivo Julián Borderas Pallaruelo (AJBP), Caja 447-15, Boletín de la Benéfica Hispana, año III, n. ${ }^{\circ}$ 6, p. 3, agosto de 1947. 


\section{Imagen 4}

Listado de los servicios médicos disponibles en la Benéfica Hispana en agosto de 1947. Aurelio Almagro Gracia aparece ya como "médico honorario".

\section{BENEFICA HISPANA}

SANATORIO Y MATERNIDAD Marsella No. 58

Telólonos: $14-49-75-36-74-90$

$$
\text { SERVICIOS MEDICOS }
$$

Dr. COLCHERO; Lunes. Martes y Jueves de 9.30

a $10.30 \AA$. M.
DA. FANDINO: Miércoles. Viemes y Sábados do 12 a 1 .

Dr, MOLAS: Diaria do $5.30 \propto 6.30$ P. M

Dr. ALMAGRO: Módico honorario

DA. ALMAGR MECIALIDADES

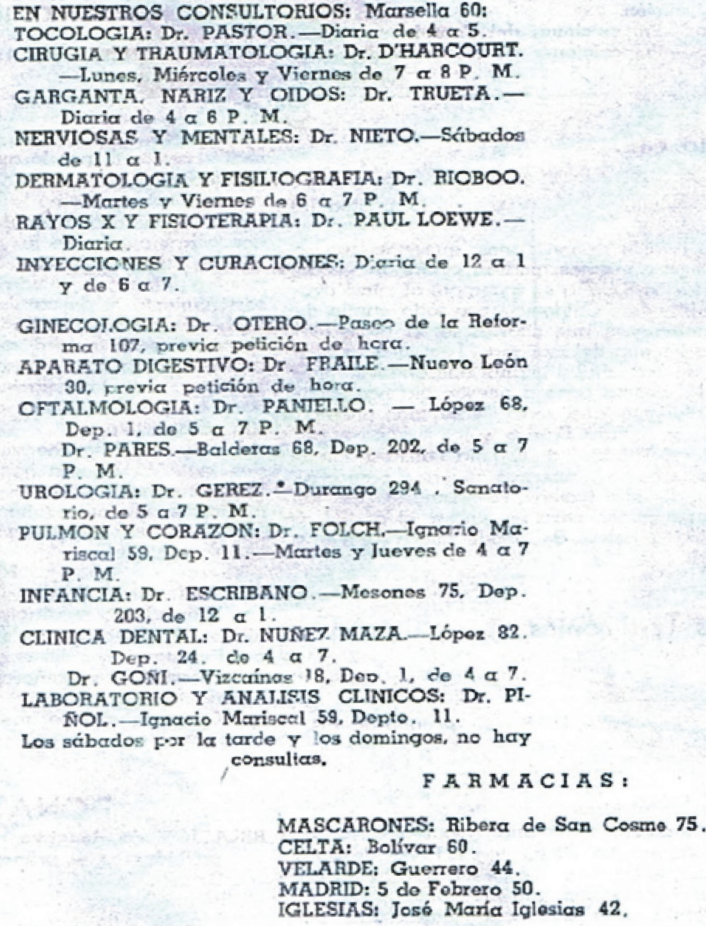

Fuente: Fundación Pablo Iglesias ${ }^{39}$.

39. En el documento se pueden observar todo tipo de detalles, como los médicos y especialistas, sus horarios y las instalaciones propias y asociadas de la Benéfica Hispana. FPI, AJBP, Caja 447-15, Boletín de la Benéfica Hispana, año III, n. ${ }^{\circ}$ 6, p. 24, agosto de 1947. 


\subsection{La Minoría Parlamentaria Socialista}

El exilio de cientos de militantes y dirigentes del PSOE dibujó un nuevo mapa político tanto en la estructura interna del partido como en las instituciones del Gobierno republicano. La pugna por el poder entre Juan Negrín e Indalecio Prieto inundó toda la política del exilio socialista y México fue durante la década de 1940 el escenario de sus diferencias. Ya hemos visto que el primero en golpear fue Indalecio Prieto quien se hizo cargo del yate Vita permitiéndole el control y funcionamiento de los recursos destinados para el auxilio da los refugiados españoles, lo que originó a su vez una disputa entre las diferentes instituciones mencionadas en páginas anteriores. Seguidamente, también en 1939, el grupo prietista organizo la Delegación del PSOE en el exilio, un organismo que dos años más tarde elegiría una nueva Comisión Ejecutiva sin el apoyo de los seguidores de Juan Negrín. Además, Indalecio Prieto, establecido en México a diferencia de su rival que permaneció en Londres, fundó el 21 de abril de 1940 el Centro Cultural Pablo Iglesias donde se agruparon aquellos miembros del partido residentes en México.

A raíz de la aparición de este organismo iba tener lugar uno de los puntos de inflexión dentro de la disputa interna de los socialistas en México: la decisión del Centro Cultural Pablo Iglesias de cerrar la puerta a cualquier colaborador de Juan Negrín. En este sentido, el 10 de septiembre de 1941 se negó la entrada a dos líderes históricos cercanos al grupo de Negrín: Ramón González Peña y Ramón Lamoneda, este último, secretario del Grupo Parlamentario Socialista. Ante esta decisión ambos dirigentes decidieron constituir el 21 de diciembre de 1941 el Círculo Cultural Jaime Vera con el fin de contrarrestar el creciente poder de Indalecio Prieto.

Por si no fuera poco la disputa existente, la división de poderes llegó también al Grupo Parlamentario Socialista, es decir al conjunto de diputados del PSOE en las aún vigentes Cortes republicanas. El grupo mayoritario apoyó a Indalecio Prieto a través de la Minoría Parlamentaria Socialista y un sector más reducido se refugió en la Agrupación Parlamentaria bajo el control de Juan Negrín. De esta manera, se configuró una división de poderes entre ambas facciones socialistas que dio a lugar a duros enfrentamientos y a una continua pelea por el poder que finalizará en 1945 con la dimisión de Juan Negrín como presidente del Gobierno de la República en el exilio y su expulsión del PSOE junto a una treintena de históricos dirigentes socialistas ${ }^{40}$.

40. Aunque se trata de un breve resumen de todo el entramado político desarrollado por el PSOE en el exilio, es fundamental para entender el futuro político de nuestro 
La vida política de Aurelio Almagro Gracia en el exilio iba estar estrechamente vinculada a los socialistas establecidos en México y la polémica explicada. Desde su llegada al país Aurelio retomó sus obligaciones como diputado de las Cortes formando parte de la Minoría Parlamentaria Socialista a la que estaría ligado hasta su fallecimiento ${ }^{41}$. Su acercamiento al sector de Indalecio Prieto no es ninguna casualidad ya que desde sus comienzos Almagro Gracia había apostado por un socialismo moderado alejado de las reivindicaciones más radicales del partido. Esta posición explica a su vez la actuación como médico en los servicios médicos de la JARE, controlada por Indalecio Prieto, y la Benéfica Hispana, constituida por una mayoría de médicos socialistas inscritos en el Círculo Cultural Pablo Iglesias, donde Aurelio Almagro también participará durante sus primeros años de exilio. En este sentido no es de extrañar que Aurelio Almagro Gracia fuese uno de los diputados miembros del Círculo Pablo Iglesias que votó a favor de la no admisión de Ramón González Peña y Ramón Lamoneda el 10 septiembre de $1941^{42}$.

La veteranía, la fidelidad y las capacidades demostradas por Aurelio Almagro sirvieron para que en muy poco tiempo ocupara cargos de responsabilidad dentro del grupo de socialistas de Indalecio Prieto. El 22 de octubre de 1942 era elegido como vocal en la directiva de la Minoría Socialista, junto a Anastasio de Gracia como vicepresidente y Julián Borderas Paracuellos como presidente ${ }^{43}$. A partir de este momento las intervenciones en el seno de la Minoría Parlamentaria por parte de Aurelio Almagro serán constantes, debatiendo temas tan importantes como la reorganización del PSOE o la reorganización de la República en el

protagonista, Aurelio Almagro Gracia, quien como veremos en páginas siguientes estuvo muy presente dentro de la disputa socialista en México. Entre la producción bibliografía existente al respecto, además de consultar la biografía de los líderes socialistas ya mencionados, destacan los trabajos de P. L. Angosto (2009) y J. Hoyos Puente (2012).

41. Para el estudio de este grupo parlamentario es esencial la consulta del Archivo Personal de Julián Borderas Pallaruelo (AJBP) en la Fundación Pablo Iglesias. Dicho fondo cuenta con todas las actas de la organización, al igual que la relación de componentes en diferentes años, declaraciones, notas y manifiestos de los diferentes integrantes, permitiendo un estudio de la evolución de este grupo socialista. Como veremos Borderas Pallaruelo fue el miembro más activo dentro de la Minoría Socialista y por ello ha sido necesario la consulta de su estudio biográfico: E. SARASA BARA (2009).

42. FPI, AJBP, Caja 760-1, Minoría Parlamentaria Socialista (MPS), Actas 1941, 10/9/1941.

43. FPI, AJBP, Caja 760-3, MPS, Actas 1942, 22/10/1942. 
exilio. Respecto a esta última cuestión, debemos destacar la presencia de Aurelio Almagro en la reunión de las Cortes republicanas celebradas el 17 de agosto de 1945 en el salón de Cabildos del Palacio del Gobierno de Ciudad de México, donde, con la asistencia de 96 diputados y tras intensos debates, se aprobaba la elección de Martínez Barrio como presidente de la República y José Giral como jefe del Gobierno, apartando así a Juan Negrín del poder ${ }^{44}$.

Tan solo dos días después, el 19 de agosto de 1945 tuvo lugar una Asamblea Extraordinaria del PSOE donde fueron llamados todos los militantes residentes en México. Aunque a la cita acudieron más de 700 afiliados, incluido Aurelio Almagro, destacó la ausencia de los miembros del Círculo Jaime Vera y otros grupos minoritarios como la Federación de Agrupaciones y el Comité Central Socialista de Euskadi que tras diversas reuniones se negaron a asistir. La negativa de estos es más que entendible, Indalecio Prieto y sus partidarios habían organizado dicha reunión y como mayoría tenía como objetivo principal la absorción de todos ellos. Pese a estas ausencias, los prietistas continuaron con su estrategia y llevaron a cabo la disolución del Círculo Pablo Iglesias a favor de la Agrupación Socialista Española en México, que a partir de este momento se convirtió en el organismo representante de los socialistas en el país azteca bajo la presidencia de Indalecio Prieto, otorgando un golpe casi definitivo a los negrinistas ${ }^{45}$.

Un año después y tras la expulsión de Juan Negrín y sus aliados del PSOE, el 26 de noviembre de 1946 la Minoría Parlamentaria Socialista realizaba cambios en su dirección. Aurelio Almagro Gracia era elegido por unanimidad como presidente, acompañado de Julián Borderas como vicepresidente ${ }^{46}$. La reorganización de la directiva era otra pieza más en la estrategia de Indalecio Prieto, quien estos momentos controlaba de manera absoluta los grupos socialistas en el exilio. Es en este momento cuando Aurelio Almagro, ante semejante responsabilidad y debido a la edad y los problemas de salud, decide apartarse de su trabajo como médico en la Benéfica Hispana para ocuparse plenamente en sus tareas de dirección en la Minoría Socialista.

44. Para ver más detalles sobre el nombramiento de Martínez Barrio y el nuevo gobierno de la República, en O. Cabezas (2005), 518-519

45. La formación de la Agrupación Socialista de México se puede consultar con más detalles en O. Cabezas (2005), 525-529.

46. FPI, AJBP, Caja 760-7, MPS, Actas 1946, 26/11/1946. 


\section{Imagen 5}

Reunión de la Minoría Socialista en noviembre de 1945.

Aurelio Almagro Gracia aparece marcado con una cruz, cuarto por la izquierda.

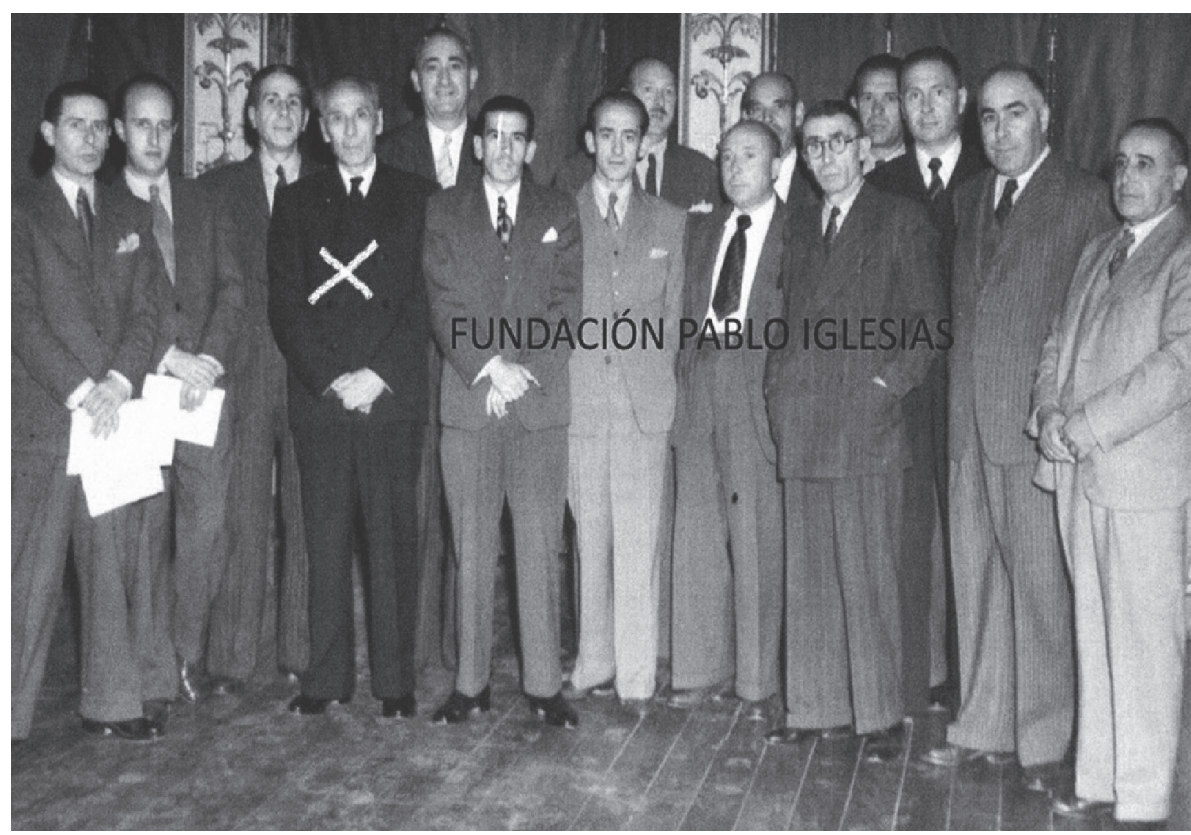

Fuente: Fundación Pablo Iglesias ${ }^{47}$.

La presidencia de Aurelio Almagro dentro de la Minoría Parlamentaria Socialista duró hasta el mismo año de su muerte en 1973. Durante los 27 años de dirección Aurelio realizó una función básicamente presencial y mediadora entre los integrantes del grupo socialista, un socialismo de base y de fidelidad alejado de los debates y luchas por el poder protagonizados por los diferentes líderes socialistas mencionados. Aunque durante los últimos años de la década de 1940 este organismo estará al servicio de Indalecio Prieto, quien se hará cargo de la Comisión Ejecutiva del PSOE en 1950, sus esfuerzos de reorganización y restauración de la República serán en vano, ya que, la consolidación del régimen franquista y el aislamiento internacional de las instituciones republicanas fueron inevitables.

47. La foto recoge la reunión de la Minoría Socialista previa al pleno del Congreso de los Diputados celebrado el 7 de noviembre de 1945 en México. FPI, Archivo Fotográfico, MPS, fotografía 029005. 
La década de 1950 no fue mucho mejor, el paso del tiempo provocó una crisis interna tanto al Gobierno republicano como en el PSOE, cada vez más conscientes de que el retorno a España de la República era prácticamente imposible. El año 1962 quedaría marcado en la memoria de los refugiados republicanos ante las muertes de dos personajes claves en la República en el exilio: Martínez Barrio e Indalecio Prieto. El primero de ellos sería sustituido por el socialista Luis Jiménez de Asúa y el segundo por Rodolfo Llopis Ferrándiz, secretario del PSOE desde 1944 y quien llevará a cabo una reorganización del partido desde los grupos establecidos en Francia en detrimento de los organismos establecidos en México.

Para el año de 1962 la Minoría Parlamentaria Socialista se encontraba en plena descomposición ante el descenso de la afiliación, el fallecimiento de muchos de sus integrantes y las diferencias con la Agrupación Socialista Española en México. Pese estas circunstancias, el 12 de octubre de 1962 Aurelio Almagro Gracia recibió un sentido homenaje por parte de sus compañeros socialistas. La iniciativa fue de Julián Borderas, vicepresidente de la Minoría Socialista, quien vio necesario "un homenaje al compañero Aurelio Almagro en mérito de su veteranía en el Partido Socialista y por los servicios prestados al mismo en sus ochenta años de edad ya cumplidos". $\mathrm{Al}$ acto acudieron diferentes miembros del PSOE establecidos en México quienes entregaron a Aurelio Almagro un álbum conmemorativo con las firmas de los asistentes al acto, las adhesiones recibidas por correo y una relación de los diputados socialistas que fueron electos en las elecciones del 16 de febrero de 1936 con la especificación de su situación en 1962. Entre el correo recibido se encontraba una emotiva carta de Rodolfo Llopis, quien recordaba los momentos de gloria vividos en Cuenca con la proclamación de la República en $1931^{48}$.

Pese a este sentido homenaje en los años posteriores la cruda realidad se adueñó de la Minoría Parlamentaria Socialista. La institución no tenía relevancia alguna y sus reuniones se celebraban únicamente en fechas de especial significación y rara era la ocasión que los actos no se iniciaban con el recordatorio a uno de los integrantes, ya fuera por enfermedad

48. Dicho álbum y varias de las cartas es lo poco que se conserva en el Archivo Personal de Aurelio Almagro Gracia en la Fundación Pablo Iglesias. FPI, Archivo personal Aurelio Almagro Gracia, Caja 828-5, Felicitaciones de la Minoría Socialista a Aurelio Almagro, 12/10/1962. 
o por el fallecimiento de los mismos ${ }^{49}$. Respecto a los últimos años de existencia de la institución, a principios de la década de 1970 fue Julián Borderas el encargado de guiar la menguada Minoría Socialista, como vicepresidente de la organización, ya que Aurelio Almagro arrastraba problemas de salud y desde mediados de 1960 realizaba una actividad meramente presencial ${ }^{50}$. Pese a su avanzada edad, Aurelio Almagro Gracia iba recibir un nuevo homenaje por parte de sus últimos compañeros, quienes dedicaron un pequeño escrito felicitando el 90 cumpleaños del veterano diputado socialista.

\section{MEMORIA ANTE EL OLVIDO}

Al borde de la vuelta de la democracia a España Aurelio Almagro Gracia fallecía el 31 de enero de 1973 en Ciudad de México a la edad de 91 años. Llegaba el final para el incansable médico y socialista que durante su larga vida defendió a capa y espada su propio ser. Aurelio Almagro curtió su socialismo abriéndose paso por el conservadurismo de su tierra, Cuenca, donde logró ser el máximo representante del PSOE y una histórica elección como diputado a Cortes en 1931. Un triunfo político, pero también personal, como médico había logrado el apoyo de gran parte de la provincia y de la ciudad de Cuenca y alrededores gracias a su dedicación en la Beneficencia Municipal.

49. La decadencia de la Minoría Parlamentaria Socialista se observa en la escasa documentación producida por la misma a través de sus actas y relación de miembros en los últimos años. Por citar algún ejemplo, en 1971 morían Ramón Lamoneda, reintegrado en el grupo, y Mariano Moreno Mateo y en 1972, Antonio Fernández Bolaños, Alberto Fernández Ballesteros y Antonio Junco Toral. FPI, AJBP, Caja 763-28, MPS, Actas 1956-1968 y AJBP, Caja 760-13, MPS, Relación de Componentes, 1971-1973.

50. La última reunión de la que tenemos constancia de la Minoría socialista sucedió el 2 de junio de 1974. A ella asistieron Mariano Saiz, el nuevo presidente; Díaz Casto, Vidarte, José Sosa, Romero Palacio, Pedro Longueira y Julián Borderas. Se adhirieron Bruno Alonso y Carlos Hernández Zancajo. FPI, AJBP, Caja, 760-10, MPS, Actas 1974, 2/6/1974. 


\section{Imagen 6}

Felicitaciones de la Minoría Socialista a Aurelio Almagro,

8 de octubre de 1971.

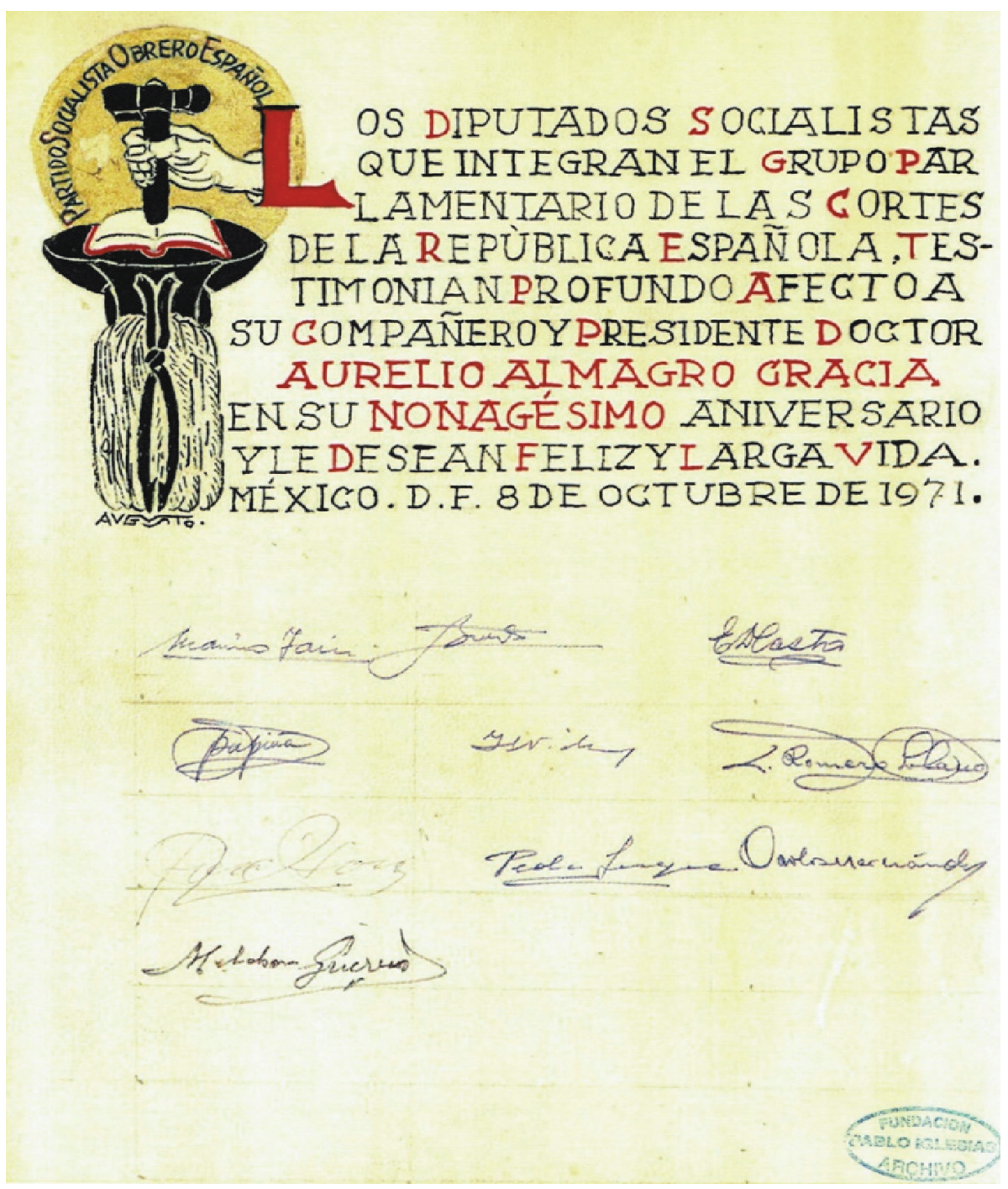

Fuente: Fundación Pablo Iglesias ${ }^{51}$.

51. FPI, Archivo personal Aurelio Almagro Gracia, Caja 828-6. Felicitaciones de la Minoría Socialista a Aurelio Almagro, 8 de octubre de 1971. 
Al igual que otros tantos miles de republicanos el golpe de estado fascista del 18 de julio de 1936 marcará por siempre la vida de Aurelio Almagro. La victoria franquista lo separó de su tierra y de su familia, ya que nunca volvería a ver a tres de sus hijos. Su camino hacia el exilio estuvo plagado de espinas y una de ellas se encontraba en Francia. La breve estancia en los caóticos campos de refugiados franceses costó la muerte de su esposa, Amalia Tello y a nuestro protagonista, una enfermedad respiratoria que le acompañó toda la vida. Con seis décadas a las espaldas Aurelio logró llegar a tierras mexicanas con la sensación de que todo estaba perdido: su familia, su tierra, su sentir socialista y su vida. Sin embargo, como ave fénix que resurge de las cenizas, Almagro Gracia curó sus heridas y prendió la mano a los cientos de exiliados que como él habían sido despojados de su patria. Un viaje que puede considerarse como una continuidad de su vida en España, pero con distintos protagonistas, lugares y emociones. $\mathrm{Y}$ es que, los hechos vividos, las experiencias inmediatas, no le hicieron desarraigarse de su pasado.

Ya en México continuó su carrera como médico ayudando a los más necesitados, una actitud que le valdría el reconocimiento profesional de los compañeros de la medicina del exilio y de los propios beneficiarios de los servicios de Aurelio Almagro. Además, alejado de la disputa que inundaba su segunda casa, el PSOE, continuó con la esperanza de volver a España de la mano de su partido, de la República y de todos sus compañeros, aquellos a los que se unió para dirigir la Minoría Parlamentaria Socialista. El paso de los años hizo mella y creó una sensación de estar viviendo una doble vida, la de antes y la después del exilio. Sin embargo, Aurelio Almagro Gracia fue uno de aquellos exiliados, que lejos de separar ambas vidas decidió unirlas a través de sus sentimientos más importantes, la medicina y el socialismo. 


\section{Imagen 7}

Aurelio Almagro Gracia en Ciudad de México, años 60.

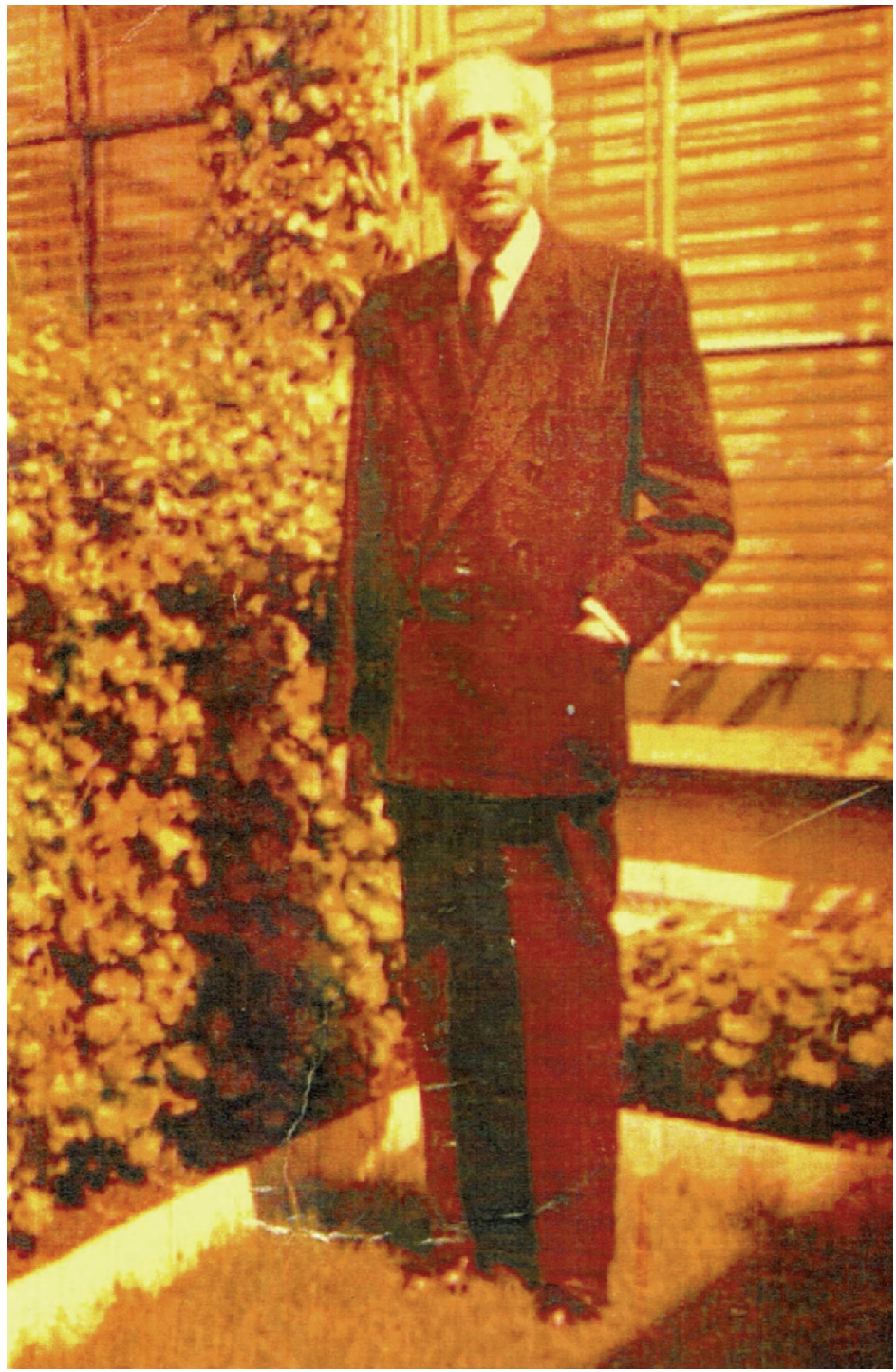

Fuente: Fundación Pablo Iglesias ${ }^{52}$.

52. FPI, Archivo personal de Aurelio Almagro Gracia, Caja 828-6. Aurelio Almagro Gracia en Ciudad de México, años 60. 


\section{Imagen 8}

\section{Aurelio Almagro Gracia en Ciudad de México.}

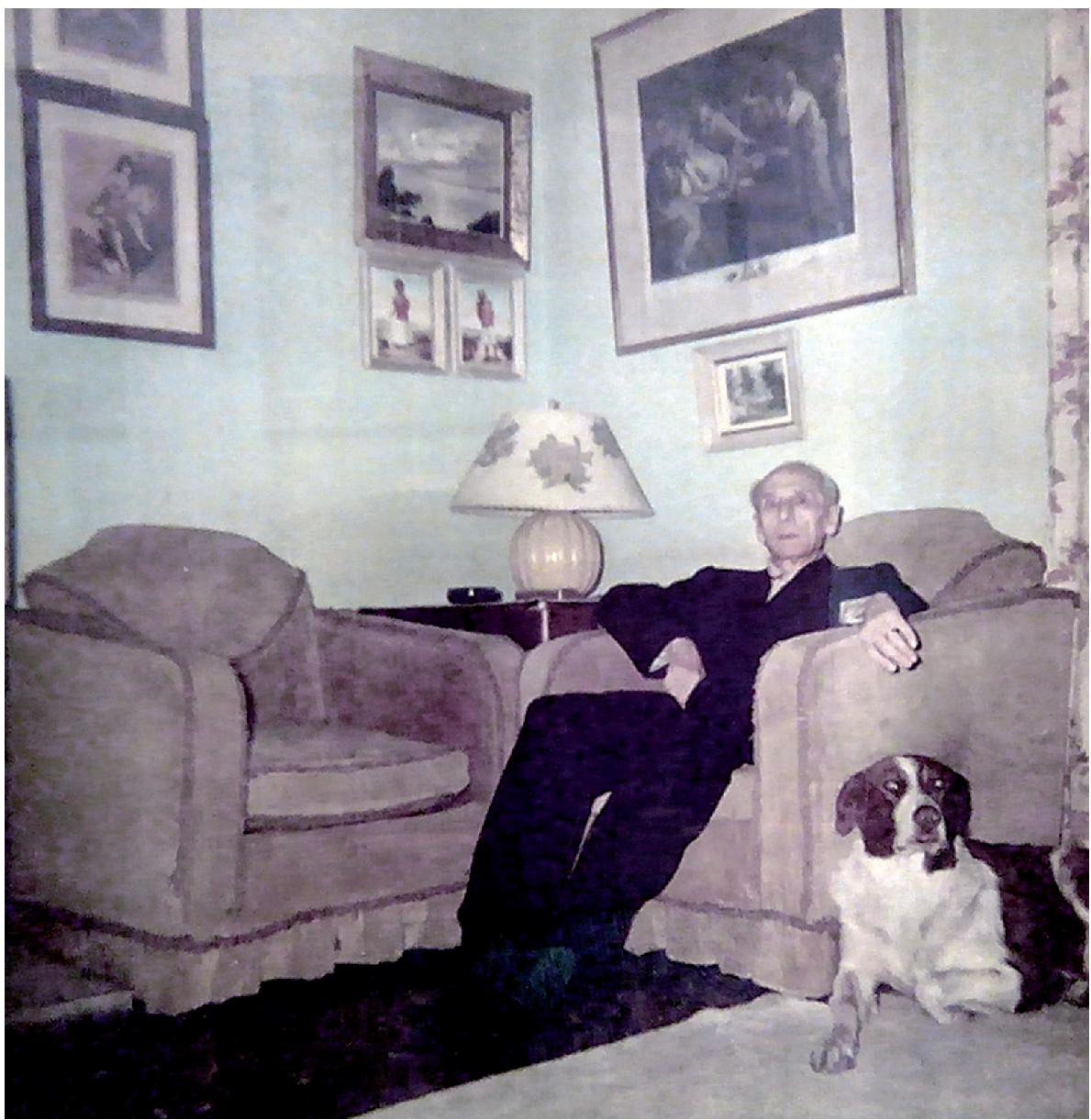

Fuente: Familia Vega Almagro. 


\section{BIBLIOGRAFÍA}

Abellán, José Luis y Mancebo Alonso, María Fernanda (1989), José Puche Álvarez (1896-1979): Historia de un compromiso. Estudio bibliográfico y científico de un republicano español, Generalitat Valenciana, Valencia.

Álvarez Rey, Leandro (2009), Los Diputados por Andalucía de la Segunda República, 1931-1939, vol. 1, Fundación Centro de Estudios Andaluces Consejería de la Presidencia de la Junta de Andalucía, Sevilla.

Angosto, Pedro Luis (2009), La República en México: Con plomo en las alas. 1939-1945, Espuela de Plata, Sevilla.

Barruso Barés, Pedro y Martín Nájera, Aurelio (2010), Diccionario biográfico del socialismo español (1879-1939), 2 vols., Fundación Pablo Iglesias, Madrid.

Cabezas, Octavio (2005), Indalecio Prieto, Socialista y español, Algaba ediciones, Madrid.

Girón, Fernando y Barranco, Enriqueta (2011), “El Servicio Médico-Farmacéutico de la Junta de auxilio a los republicanos españoles, delegación de México", Dynamis, 31, pp. 159-181.

GonzÁlez García, Alberto (2016), "La actividad de las matronas de la Beneficencia Municipal en Cuenca a comienzos del siglo XX desde la perspectiva de género", Historelo. Revista de Historia Regional y Local, 16, pp. 228-270.

Herrerín, Ángel (2007), El dinero del exilio. Indalecio Prieto y las pugnas de posguerra (1939-1947), Siglo XXI, Madrid.

Hoyos Puente, Jorge (2012), La utopía del regreso. Proyectos de estado y sueños de nación en el exilio republicano en México, Colegio de México, Ciudad de México.

López Villaverde, Ángel Luis y SÁnchez Sánchez, Isidro (1988), Historia y evolución de la prensa conquense (1811-1939), Universidad de Castilla-La Mancha, Cuenca.

López Villaverde, Ángel Luis y Valle Calzado, Ángel del (1990), "Masonería conquense durante la II República: "El Triángulo Electra", Revista Historia Cuenca, 36, 59-70.

López VillaVerde, Ángel Luis (1997), Cuenca durante la II República: elecciones, partidos y vida política, 1931-1936, Diputación Provincial, Cuenca.

Mateos, Abdón (2009), La Batalla de México. Final de la Guerra Civil y la ayuda a los refugiados, 1939-1945, Alianza Editorial, Madrid.

Moradiellos, Enrique (2006), Don Juan Negrín, Ediciones Península, Barcelona.

Ordóñez Alonso, Magdalena (1997), El Comité Técnico de Ayuda a los Republicanos Españoles. Historia y documentos, 1939-1940, Instituto Nacional de Antropología e Historia, Ciudad de México.

Ortega Prieto, Miguel Ángel (1987), “Las elecciones de la Segunda República en Cuenca, el papel del continuismo", Revista de la Facultad de Geografía e Historia, UNED, 1, pp. 243-259. 
SARAsa BARA, Enrique (2009), Julián Borderas Pallaruelo: Una historia del socialismo y del exilio español (1899-1980), Gobierno de Aragón, Zaragoza.

Velázquez Hernández, Aurelio (2014), Empresas y finanzas del exilio. Los organismos de ayuda a los republicanos españoles en México (1939-1949), El Colegio de México, Ciudad de México. 